\title{
Electronic textbooks: didactic aspect
}

\author{
Elena O. Ivanova ${ }^{1}$ and Irina M.Osmolovskaya ${ }^{1, *}$ \\ ${ }^{1}$ ISED RAE, Laboratory of General Issues of Didactics, 105062, Moscow, Russia
}

\begin{abstract}
The modern process of training proceeding in the information and education environment demands a textbook of a new format differing from that one of a traditional paper book. Research has shown that a new textbook is a specially designed subject information and education environment. Filling of this environment (the textbook - navigator, the textbook script, a set of materials for independent work, etc.), structuring information (as the script of an educational process, the designer of a process of training, the integrator of the specified types) is shown in the article. Characteristics of textbooks of a new generation are provided: orientation towards realizing the complete process of training from positing aims to a reflection of results, ensuring the maximum independence of pupils, accounting of specific features of pupils, granting opportunities of creation by pupils of an own educational product. Components of the subject information and education environment are presented: subject and target, substantial and organizational, estimated and reflexive components. The reformative and constructive tasks providing an activity orientation of the electronic textbook are considered.
\end{abstract}

Active development and introduction of electronic textbooks for secondary school and higher institutes of education occurs now in Russia. This process is natural in the conditions of an amplifying influence of information on the life of each person and fast development of information and telecommunication technologies.

It is possible to say about the process of training that it does not only come under influence of information and education environment (IEE), but it is also completely shipped in it: an activity of all subjects of a process of training is developed in an information environment. A teacher, preparing a lesson, repeatedly addresses to information and education environment resources, creates a subject environment in which pupils can work, organizes work of pupils in an information environment. Pupils have an opportunity to solve arising informative problems independently using Internet resources, including discussions at forums, on pages of social networks. A system of mass open online courses is being developed actively, which allow a trainee designs and realizes an individual education trajectory, corresponding to his own cognitive requirements.

The process of training in information and education environment demands a textbook of a new format, which differs from traditional paper one. The research has shown that a new textbook is an electronic textbook representing specially designed subject information and education environment.

Subject information and education environment is understood as a set of information, methodical and technical resources created by subjects of education providing achievement of objectives of training in a concrete subject. Three types of subject information and education environment are allocated: 1) a script of a process of training; 2) a designer of a process of training; 3 ) integration of a script and a designer.

It is preferable to integrate scenario expansion of process of training and conditions for independent designing of trainee's own process of training in an electronic textbook as research has shown.

Subject information and education environment considered as a textbook for comprehensive school has to include electronic resources of different didactic appointments for this purpose:

- a navigator textbook with a main function to orientate trainee in subject information and education environment (it is a summary of the main content of a subject as in encyclopedic materials, which reveals in what electronic grant to find training exercises, how to carry out an inspection of digestion of material, what directions to enrich a studied material in and what electronic resources address to for this purpose, etc.);

- a script textbook of a process of training with the main function to manage the cognitive activity of trainee. Special methods of management of education cognitive activity of pupils are used for this purpose (formulation of an original key question causing interest of pupils at the beginning of an interpretation of a material; acquaintance to a course of expansion of a studied fragment of a training material; types of educational actions which should be mastered; modular representation of a material and check of assimilation after each module);

\footnotetext{
Corresponding author: irmos77@list.ru
} 
- a set of materials for independent work, including various cases representing (in a text's and also multimedia's form) life situations in which it is necessary to find an adequate way of action;

- training materials directed to work off basic skills of a subject;

- test materials allowing to define accurately how successfully was acquired a subject or a training course;

- electronic materials intended for deepening and enrichment of a studied material;

- subject information and education environment's fragments allowing to organize communication of trainee with each other, with experts in the studied area, consultation with the teacher (various forums, remote seminars, and conferences).

An environment - designer allows a pupil to design a content of education, enriching him with a material interested only to him, choosing ways of interpretation, tasks for fixing material corresponding to psychological features of a pupil. For this purpose variability of interpretation and fixing of a training material, including depth of material is provided in a textbook.

It should be noted self-sufficiency of an electronic textbook that demands development of it as a multidimensional text with a system of hyperlinks, animated inserts, video, and audio- materials, a complex of test tasks which result in performances become known to a trainee and a teacher at once. In this regard, it should be noted that development of an electronic textbook and a textbook on a paper basis is essentially various. This results from the fact that there are different forms of expansion of contents in paper and electronic textbooks. A hypertext of an electronic textbook is nonlinear, multidimensional hierarchically structured interpretation of text and non-text information. Routes of reading of a hypertext depend on an understanding of information by a trainee and its cognitive motivation.

Sequential presentation of information in a paper textbook requires a different way of working with it: "one-dimensional" reading, following a long period of explanations, evidence, regardless of subjective information's appeal. The technology of creation of similar textbooks is well-known. However, psychological features of modern school students (clip thinking, screen culture) do work with paper textbooks harder and harder. It is possible to consider the "electronic forms of textbooks" created now, as a palliative in which a paper textbook is submitted in a digital format and it is studied by means of devices reproducing information - readers, tablets, computers. Besides, electronic appendices to textbooks are actively developed.

Studying of electronic forms of textbooks for comprehensive school offered by Drofa publishing house has shown that possibilities of an electronic textbook in them aren't used completely. Textbooks represent texts absolutely identical to texts of paper textbooks with realized possibility of increasing in illustrations, inclusions of audio fragments, receiving instant feedback on performing of exercises. Essential changes haven't happened in textbooks [1].
Consideration of electronic appendices to textbooks for elementary and secondary school, gives us the chance to draw some conclusions:

1) Learning material is stated exclusively in an explanatory and illustrative manner in digital applications: a text duplicating contents of the paper textbook is being read by a professional announcer and is followed by an illustrative row in the form of a set of drawings, tables, animated inserts, video fragments.

2) Tasks to consolidate and check understanding of the material are of reproductive nature. There are tests with a choice of an answer (an answer can be submitted in an illustrative form), tasks with establishing compliance, elementary didactic games.

3) A number of materials to the paragraph is limited, materials are monotonous in a form (an explanatory and illustrative statement, reproductive reproduction) [2].

We will present below some characteristics of an electronic textbook considered as the textbook of new generation providing successful development of the content of education in information and education environment, answering calls of time and requirements of a trainee.

The textbook of a new generation has to create conditions for realization of the complete process of training: from a statement of purposes to reflection of results. It is important not to be limited only to a consecutive statement of information on a subject matter for this purpose, and it is obligatory to turn on a device of assimilation of this information. Moreover, it is possible to speak about a textbook as a training process model. His studying has to allow pupils to set an object of own cognitive activity, to acquire a content of education, to fix, carry out self-checking and a reflection. It is expedient at the same time to consider a content of education in line with a culturological concept of maintenance of comprehensive secondary education (V.V. Kraevskii, I.Y. Lerner, M.N. Skatkin), including in it knowledge, ways of action, an experience of creative and valuable and semantic activity [3].

Textbooks of a new generation are textbooks providing maximum independence of pupils in organizing individual, group, frontal kinds of activity. For this purpose, a textbook, along with a task which is performed during group work joins algorithm of an organization of activity. For example, read a task, discuss it in couples, and write an answer in a table to which you have come together; unite in groups of 6 persons to discuss answers received in each group. If answers differ, try to prove own correctness, having adduced arguments "pro" the answer. Write down arguments to a specially allotted place in a textbook. At the same time, a picture of opinions of all groups of pupils can be generated on a computer of a teacher that will allow revealing a course of thought of pupils, possible mistakes, a level of formation of abilities of an argument.

Textbooks of a new generation are textbooks considering specific features of pupils, allowing to construct individual trajectories of training, i.e. textbooks in which material is stated variably. Variability can mention only tasks for fixing and 
generalization of material when, for example, in physics, tasks are offered to design a device which helps to show any phenomenon or process at a lesson; to construct model of a technical device, to write an essay on development of these or those scientific representations, to think up several tasks of a subject, etc. At the same time, variability can be expanded to insertion of distinctions into a statement of a training material which will be presented at the different level of complexity, enriched with various fragments, focused on figurative or logical thinking of pupils. Technical features of an electronic textbook give the chance to realize variability of training as increasing in a volume of a textbook in general, a number of pages and, respectively, his weight isn't required. Each pupil can choose that option of material which corresponds to his specific features, abilities, and tendencies to studying.

An electronic textbook has to give to pupils an opportunity of creation of an own educational product which can be included in a content of a textbook and be used by the subsequent generations of pupils. An electronic textbook is to include interesting tasks demanding creative approach to a decision, fantastic stories, for example, "Life without the force of friction ", info graphics of a studied material accurately and briefly stating an essence, etc. An electronic textbook is mobile, dynamic, inclusion and withdrawal of separate fragments are easily made from it. Perhaps, electronic textbooks should be added with workbooks on a paper basis which may include those tasks that can't be executed in IEE, for example, promoting a development of motive functions of trainees - to paint, lead round on a contour, etc.

A modern textbook has to be intended for implementation of the process of training within system and activity, competence-based approach, therefore, to give a chance to a pupil to apply acquired knowledge to the solution of life situations.

A digital format of information, allowing to curtail large volumes of information and to include multimedia, gives the chance to use case-study and to carry out a situation analysis of the material presented in the form of description of true-life stories, vital problems in a course of training.

An electronic textbook enables to organize blended learning, which is regarded as a combination in a process of teaching traditional lessons, where a teacher and a student can communicate directly in a classroom, and sessions conducted through information and communication technologies. An electronic textbook as subject information and education environment may be required to work on the model of "the flipped classroom". This model assumes pre-study students' homework, for example, viewing specially developed video lectures. Work with this material will be organized in a class: discussion, debate, exercises. Thereby cognitive activity of trainee is stirred up, conditions are created for their interaction when performing group tasks of theoretical or practical character.

When using the model "the flipped classroom" students have an opportunity for a detailed study of a specially developed, updated content of an electronic textbook. Students can pause to reflect, they can return to disputed or unclear points, consult other recommended resources. Subject information and education environment thereby promotes successful independent cognitive activity, creates conditions for productive work of students in class with a teacher and classmates [4].

Consider features of an electronic textbook, as subject information and education environment professional education on the example of higher pedagogical education. One of the major problems in the development of an electronic textbook for higher school is its polyfunctionality. In addition to information functions, it aims to provide practical, professional orientation of students' knowledge, their introduction in a "professional context". At the same time, it is necessary to create conditions for use of subject knowledge of students in the practice of a holistic process of solving cognitive and professional issues, and the synthesis of knowledge, beliefs and practices, i.e. development of competences. Therefore, subject information and education environment as a script of a process of training and information and education environment as a designer of a process of training be allocated only in some cases.

From this position, subject information and education environment deploys education process in higher education in such a range of public and professional relations and to logic, which is characteristic of pedagogical activity. An electronic textbook allows representing a subject content of different facets (personal, social, vocational, moral), which are fundamentally important for the professional and personal identity of students. In higher education social reality often is veiled, and training is presented only as a process of transmission and assimilation of information. Therefore, it is important in the present conditions in each subject to develop pedagogical orientation of students, to provide them with experience in solving various problems, i.e. to transfer from a state of passively receptive student in the status of the future specialist, actively and consciously preparing for specific professional activities.

An electronic textbook should contain variable assignments, ensuring that, as students' independent work and classroom work. It is possible to offer:

a) video recordings of lessons and educational activities (or their fragments), with real teachers, pupils, themes. There are a lot of such videos on the Internet today. The subject information and education environment is based on the pedagogical goals, allowing using resources most effectively. For example, it may be carrying out open lessons by winners of the competitions "Teacher of Year" in various objects, with pupils of different age, with various styles of pedagogical interaction, educational technologies, etc. This diversity allows not only selecting a content corresponding to a field of study but also to meet interests of students. In addition, based on the data resources of information and education environment is possible to organize a systematic analysis of a target problem. A teacher thus sets the "reference point"; analysis itself and its reason is a problem of students; 
b) a set of articles, texts, regulatory documents and references, a study of which will provide absorption and extension of subject knowledge of students. In this case, it is possible to solve several pedagogical problems, among which in the present context the most significant is a development of information competence of students, specific skills in the information area. Also, there is a formation and awareness of personal position, professional information about the place and role of participants of educational process;

c) address of Internet sites where students can obtain the necessary accurate subject information in the form that best suits their psycho-physiological characteristics.

Another feature of electronic textbooks for high school is to focus on creating conditions for independent cognitive and practice-oriented activity of students, development of their personality as current (academic) and future (professional) activity. Education related to the implementation of a personal component of an educational content, subjective position of students, suggests an activity, capacity for reflection, freedom of choice and responsibility for solving it, tolerance, selfdevelopment, self-esteem. Therefore, it is reasonable to develop and include in a content of an electronic textbook knowledge of different types:

1) methodological knowledge in a respective academic discipline and in education or scientific research;

2) declarative knowledge about phenomena, events, properties of objects, the dependency;

3) procedural knowledge that allows adjusting actions;

4) knowledge of techniques and methods of search, processing and use of information when making decisions (including information literacy).

It is advisable to supplement an electronic content of subject information and education environment knowledge about effective virtual technologies that address specific educational tasks to perform different kinds of activities. For example, a virtual constructor education electronic resource, which allows students to research a subject area, receiving information relevant to their educational needs.

Selection of a content of an electronic textbook, as subject information and education environment should be made in view of its components:

- subject-target component that provides inclusion of students in the learning process and creation of cognitive motivation and goals connected with the development of ability to learn;

- substantial-organizational component, including an invariant and variable content of education and methods.

- estimated-reflexive component of information and education environment which allows 1) to collect, store, recycle, upgrade depending on goals the most important (by some criteria) results obtained by student in a learning process; 2) to carry out a reflection result; 3 ) to implement teaching assessment of results (a criteria known in advance to students) and to make necessary correction.

In accordance with these provisions in an electronic textbook should be submitted to the following blocks:
- information, based on hypertext technology, which is invariant content of education and its variable extension (through hyperlinks or selected electronic educational resources);

- organizational and procedural block that includes variable constructed tasks designed to assimilate information (both invariant and variable components of educational content), as well as means of reflection and assessment of results. Special attention should be paid to interactivity of content, its multimedia characteristics;

- personal (personal account), which can be built on the principle of student portfolio (collector, working papers, reflection), and include information and telecommunication means of organizing their own knowledge;

- communicative, provide information and evaluation of interaction both with a teacher and with classmates;

- teacher's that will allow a teacher to continuously monitor students' cognitive activity.

Consider the examples of tasks that provide activitybased orientation of an electronic textbook on pedagogy, which was tested during the experimental work.

Transformative tasks related to analysis, generalization, and systematization of information, assessing its consistency and compliance objectives. For example: "Find on the Internet 5 definitions for each of the concepts: "education", "training", "upbringing", "development", "socialization"; highlight key words characterizing each concept; make your own definition of each concept; render a graphical image (the cluster graph, Euler circles) of the correlation of the processes described by these concepts".

This type of task allows students to construct their learning process. They specify the purpose of the task and identified need for information; conducted research and worked with it as it was more convenient and familiar, carried out a reflection.

Constructive tasks associated with implementation of personal positions on an issue, a problem. Depending on complexity of a material and preparedness of students, a task can be specified:

- in depth of study - from a material of a single source to any number that suits students.

- sources of information - from text to selection between texts, video, charts;

- methods of design - from free text field to a tabular, graphical or schematic forms.

Examples: 1. "Learn about features of education in Athens and Sparta. Write an essay on "What ancient education we use or could use in our time". Prepare for a "roundtable meeting".

2. "Please read the article of M. R. Bityanova "Portrait of a modern Child" (in printed form or follow a link that was given by a teacher). Answer the following questions: What can education do to teach this child? Must a teacher and a psychologist pay attention to while working with a child, teaching staff, parents? [5]

Scientific research has shown that this form of tasks for work with an electronic textbook provides good assimilation of educational content, variability of depth and volume of studied information, a formation of skills 
of independent cognitive and reflective activity in the professionally-oriented situations.

Summing up, it should be noted that development of an electronic textbook as a subject information and education environment requires didactic responses to questions about didactic bases and methodology of selecting and designing a content of education, about a form of its presentation in a textbook, about methods and forms of organization of work of students and teachers, about information abilities necessary for them, etc. [6]. It should arises in mind that an electronic textbook does not present in digital form a text of a paper textbook, it is, indeed, subject information and education environment, which developed in this form from the beginning.

\section{References}

1. A.V. Peryshkin, Fizika 8 klass. Interaktivnyi content (Drofa, Moskva, 2015) [In Rus]

2. M.M. Razumovskii, S.I. L'vova, V.I.Kapinos, Russkii yazyk. 6 klass. Interaktivnyi content (Drofa, Moskva, 2015)v[In Rus]
3. V.P. Kanakina, and G. Goretskii, Russkii yazyk. 3klass. Ch.2 (Prosveshchenie, Moskva, 2014) [In Rus]

4. M.I. Moro, M.A. Bantova, and G.V. Bel'tyukovai., Matematika. 3 klass,.ch. 2. (Prosveshchenie, Moskva, 2014) [In Rus]

5. Teoreticheskie osnovy soderzhaniya obshchego srednego obrazovaniya (Pedagogika,Moskva, 1983) [In Rus]

6. E.O. Ivanova, Obrazovanie I nauka, 5, 118 (2015) [In Rus] 